\title{
Qualidade água na bacia hidrográfica do Rio das Garças/MT para fins de irrigação
}

A água para fins da agricultura depende tanto da quantidade como da qualidade. Monitorar as variáveis físico-químicas da água é necessário, pois a utilização de água de irrigação de baixa qualidade pode acarretar problemas nos sistemas de irrigação, causar degradação do solo e interferir na absorção de nutrientes pelas plantas cultivadas. A qualidade das águas para fins de irrigação se define basicamente nos critérios de salinidade, sodicidade toxicidade e parâmetros microbiológicos. O objetivo do trabalho foi avaliar a qualidade da água para irrigação na Bacia do Rio das Garças situado no estado de Mato Grosso. Os dados utilizados nesse estudo foram obtidos por meio do Relatório de Monitoramento de Qualidade de Água elaborado pela Secretaria de Estado de Meio Ambiente de Mato Grosso-SEMA-MT. Os resultados obtidos apontam que a qualidade da água da bacia do Rio das Garças no período estudado é favorável para uso na Irrigação.

Palavras-chave: Monitoramento; Recursos Hídricos; Agricultura.

\section{Water quality of the Garças River basin, Mato Grosso State/Brazil, for use in irrigation}

Water for use in agriculture depends on quantity and quality. Monitoring the physico-chemical variables of water is necessary because using low quality irrigation water will cause problems in irrigation systems, cause soil degradation, and problems in nutrient uptake by cultivated plants. The water quality for use in irrigation depends on salinity, sodicity, toxicity and microbiological parameters. The objective of this study was to evaluate the water quality for use in irrigation in Rio das Garças, located in the state of Mato Grosso, Brazil. The data used in this study are from the Water Quality Monitoring Report prepared by the Environment Department of the State of Mato Grosso, SEMA-MT. The research concluded that the water quality of the Garças River during the study period is feasible for use in irrigation.

Keywords: Monitoring; Water Resources; Agriculture.

Topic: Engenharia Ambiental

Reviewed anonymously in the process of blind peer.
Received: 06/12/2019

Approved: 12/01/2020

Claudineia Aguiar de Souza (D)

Universidade do Estado de Mato Grosso, Brasil

http://lattes.cnpq.br/4818450294272956

http://orcid.org/0000-0003-1578-2300

claudineia.souza@unemat.br

Tadeu Miranda de Queiroz

Universidade do Estado de Mato Grosso, Brasil

http://lattes.cnpq.br/2582121765769124

http://orcid.org/0000-0002-1959-7658

tdmqueiroz@unemat.br

Referencing this:

SOUZA, C. A.; QUEIROZ, T. M.. Qualidade água na bacia hidrográfica do Rio das Garças/MT para fins de irrigação. Revista Ibero Americana de Ciências Ambientais, v.11, n.1, p.157-164, 2020. DOI:

http://doi.org/10.6008/CBPC2179-6858.2020.001.0015 


\section{INTRODUÇÃO}

A existência da água é essencial para a continuidade da vida em todo o planeta, bem como para o desenvolvimento de grande parte das atividades realizadas pelo homem, sejam elas urbanas, industriais ou agropecuárias. Em razão de uma série de características físicas, químicas e microbiológicas que lhe são peculiares, a água pode ser considerada o bem mais precioso oferecido pela natureza (COSTA FILHO, 2006)

Nos últimos anos, a humanidade vem se defrontando com uma série de problemas econômicos, sociais e ambientais, dentre os quais as preocupações com os recursos hídricos adquirem especial importância, tendo em vista que a demanda por água está se tornando cada vez maior e a sua qualidade vem sendo degradada de maneira alarmante, sobretudo nas áreas mais urbanizadas (OLIVEIRA, 2014). Essa crescente demanda para atender os diferentes usos da água, resulta em prejuízo na qualidade e na disponibilidade de água, sendo notória a necessidade constante do monitoramento dessas alterações, de forma a não comprometer seu aproveitamento múltiplo e minimizar os impactos negativos do ambiente (BRAGA et al., 2006).

A água para o uso na agricultura depende disponibilidade tanto em termos quantitativos como também qualitativos, a qualidade da água é definida por meio de suas características físicas, químicas e microbiológicas. O Conselho Nacional de Meio Ambiente, por meio da Resolução CONAMA 357, de 17 de março de 2005 estabeleceu condições de qualidade para o enquadramento dos corpos hídricos, separandoos em classes de acordo com os seus usos e fixando limites superiores ou inferiores para os elementos existentes na água. Cada tipo de uso pressupõe uma maior ou menor exigência de qualidade da água. Para as águas doces, foram criadas 5 categorias, a classe especial e as classes de 1 a 4 , em uma ordem decrescente de qualidade. Para uso na irrigação as de classe 1 são para irrigação de hortaliças e de frutas que crescem rente ao solo e que sejam ingeridas cruas sem remoção de película; as de classe 2 para irrigação de hortaliças e plantas frutíferas, parque e jardins; e as classe 3 para irrigação de culturas arbóreas, cerealíferas e forrageiras.

A qualidade da água de irrigação não influencia somente as culturas por elas irrigadas, mas também interferem no solo onde elas se desenvolvem, podendo modificar sua composição e possibilitar a contaminação por microrganismos patogênicos (ALMEIDA, 2010). Os problemas causados pela qualidade da água podem ser resumidos nos seguintes efeitos principais: salinidade, sodicidade e toxidez às plantas cultivadas (AYERS et al., 1991).

Em termos de gestão hídrica, o maior desafio em uma bacia hidrográfica é a garantia dos múltiplos usos para as atuais e futuras gerações. Segundo a Agência Nacional de Águas a irrigação é o setor que mais consome água no país, o monitoramento quali-quantitativo dos recursos hídricos de forma sistemática se faz necessário para promover e sensibilizar o uso racional dos mesmos, em Mato Grosso, estado de potencial agrícola, usar a água de forma racional é fundamental para promover o aumento da produtividade sem comprometer os recursos naturais, e avaliar a qualidade da água para irrigação na Bacia do Rio das Garças se faz necessário para a melhor gestão da atividade agrícola na região. Neste trabalho avaliaremos algumas 
variáveis relevantes para os fins de irrigação como os íons potássio (K), sódio $(\mathrm{Na})$, cálcio $\left(\mathrm{Ca}^{2+}\right)$ e magnésio $\left(\mathrm{Mg}^{2+}\right)$; dureza total e a condutividade elétrica (CE) que podem causar danos nos sistemas irrigantes (AYERS et al., 1991). A toxicidade para algumas culturas analisando os íons cloretos ( $\mathrm{Cl}^{-}$) e os parâmetros microbiológicos que podem causar contaminação com organismos patogênicos (ALVAREZ, 2009).

\section{MATERIAIS E MÉTODOS}

\section{Área de estudo}

O Estado de Mato Grosso possui três importantes Regiões Hidrográficas do Brasil: Região Hidrográfica Amazônica, Região Hidrográfica Tocantins-Araguaia e Região Hidrográfica Paraguai (ANA, 2012). A Região Hidrográfica Tocantins-Araguaia com uma área superior a $800.000 \mathrm{~km}^{2}$ constitui a maior bacia hidrográfica inteiramente situada em território brasileiro. O Rio das Garças é um importante afluente do rio Araguaia, nasce no município de Alto Garças, passando por Guiratinga, Tesouro, General Carneiro e, finalmente, desaguando no rio Araguaia pela sua margem esquerda, na confluência dos municípios de Barra das Garças e Pontal do Araguaia. Apresenta, no total, uma área de drenagem correspondente a 13.514,81 $\mathrm{km}^{2}$, configurando uma região impactada e registrando conflitos de várias naturezas (SEMA, 2006). A estimativa populacional nos municípios pertencentes à Bacia do Rio das Garças é de 94.496 habitantes (IBGE, 2010)

As atividades econômicas desenvolvidas na região da bacia do Rio das Garças são: Agricultura, pecuária, extrativismo mineral, comércio varejista, agroindústria e ecoturismo. 0 tipo climático regional é o tropical chuvoso, caracterizado por ser um clima quente e úmido, com duas estações bem definidas, sendo um período chuvoso durante os meses de outubro a março e outro de estiagem, de abril a setembro. A precipitação média anual, na bacia é de $1.911 \mathrm{~mm}$, sendo dezembro, janeiro e fevereiro os meses com maiores valores registrados, médias de $268 \mathrm{~mm}, 263 \mathrm{~mm}$ e $244 \mathrm{~mm}$, respectivamente. Os meses mais secos são junho, julho e agosto (SEMA, 2006).

\section{Dados de Monitoramento}

Os dados do utilizados nesse estudo foram obtidos por meio do Relatório de Monitoramento de Qualidade de Água elaborado pela Secretaria de Estado de Meio Ambiente de Mato Grosso-SEMA-MT. Atualmente SEMA/MT opera uma rede de monitoramento qualitativo e quantitativo composta por 81 pontos de amostragem em todo o estado de Mato Grosso. A Bacia Rio das Garças, possui 6 pontos de monitoramento, contemplando a nascente até sua foz no Rio Araguaia. (Tabela 1). Essas estações de coleta estão cadastradas no banco de dados da Agência Nacional das Águas, e os relatórios bianuais com os dados gerados podem ser consultados no site da ANA/HIDROWEB e no site da SEMA/MT.

As coletas e suas respectivas análises foram realizadas duas vezes por ano, uma coleta no período chuvoso e outra no período seco, durante o ano de 2017. Foram utilizados os procedimentos estabelecidos no Guia Nacional de Coleta e Preservação de Amostras: água, sedimento, comunidades aquáticas e efluentes 
líquidas da CETESB (2011) os procedimentos instituídos pelo Standard Methods for the Examination of Water and Wastewater 21a edição (APHA, 2005), como referência para as coleta e preservação das amostras SEMA (2018).

Tabela1: Descrição dos pontos de monitoramento na Bacia Hidrográfica do Rio das Garças/MT.

\begin{tabular}{|l|l|l|}
\hline Ponto de Monitoramento & Município & Coordenadas Geográficas \\
\hline P1-Ponte de Cima próximo à nascente & Alto Garças & $16^{\circ} 51^{\prime} 56,9^{\prime \prime} \mathrm{S} 53^{\circ} 23^{\prime} 57,6^{\prime \prime} \mathrm{W}$ \\
\hline P2- Córrego Aldeia & Tesouro & $16^{\circ} 11^{\prime} 34,5^{\prime \prime} \mathrm{S} 53^{\circ} 40^{\prime} 29,6^{\prime \prime} \mathrm{W}$ \\
\hline P3 -Tesouro & Tesouro & $16^{\circ} 04^{\prime} 39,3^{\prime \prime} \mathrm{S} 53^{\circ} 32^{\prime} 54,1^{\prime \prime} \mathrm{W}$ \\
\hline P4- General Carneiro & General Carneiro & $15^{\circ} 43^{\prime} 37,3^{\prime \prime} \mathrm{S} 52^{\circ} 45^{\prime} 24,3^{\prime \prime} \mathrm{W}$ \\
\hline P5- Córrego Avoadeira & Barra do Garças & $15^{\circ} 52^{\prime} 39,0^{\prime \prime} \mathrm{S} 52^{\circ} 22^{\prime} 25,7^{\prime \prime} \mathrm{W}$ \\
\hline P6- Foz no Araguaia & Barra do Garças & $15^{\circ} 53^{\prime} 41,8^{\prime \prime} \mathrm{S} 52^{\circ} 15^{\prime} 25,2^{\prime \prime} \mathrm{W}$ \\
\hline
\end{tabular}

Fonte: SEMA (2018).

Os parâmetros físico-químicos de interesse para o estudo foram, potencial hidrogeniônico (PH), sódio $\left(\mathrm{Na}^{+}\right)$, cálcio $\left(\mathrm{Ca}^{2+}\right)$, magnésio $\left(\mathrm{Mg}^{2+}\right)$, a condutividade elétrica $(\mathrm{CE})$, Razão de Adsorção de Sódio que é a relação entre Sódio e Cálcio+Magnésio (RAS), Íons cloreto $\mathrm{Cl}^{-}$e o parâmetro microbiológico Escherichia coli. As análises foram realizadas conforme as metodologias analíticas descritas na tabela 2.

Tabela 2: Metodologias utilizadas nas análises físico-químicas e microbiológicas.

\begin{tabular}{|l|l|}
\hline Parâmetro & Método \\
\hline $\mathrm{pH}$ & Eletrométrico (APHA - método 4500-H+B) \\
\hline Condutividade Elétrica (CE) & Eletrométrico (APHA - método 2510 B) \\
\hline Sódio & Cromatografia iônica (Dionex application note 141) \\
\hline Potássio & Cromatografia iônica (Dionex application note 141) \\
\hline Cálcio & Cromatografia iônica (Dionex application note 141) \\
\hline Magnésio & Cromatografia iônica (Dionex application note 141) \\
\hline Cloreto & Cromatografia iônica (Dionex application note 141) \\
\hline Escherichia coli & Método Substrato Enzimático (Colilert ${ }^{\circledR}$ ) (APHA - método 9223 B) \\
\hline
\end{tabular}

Fonte: SEMA (2018).

\section{Qualidade da água para irrigação}

A qualidade da água para fins de irrigação foi avaliada quanto sua salinidade, sodicidade, toxicidade. Foi avaliado também dado da qualidade microbiológica. Salinidade é o resultado da acumulação de sais na dissolução do solo, que pode dificultar a captação de água e nutrientes por parte da planta. O principal agente causador da salinidade do solo é a qualidade da água utilizada na irrigação. A tabela 3 expressa a restrição de uso quanto à salinidade, considerando a condutividade elétrica (CE), devido à facilidade de sua determinação, é o parâmetro mais utilizado para determinar a sua potencialidade de salinizar um solo, além dos íons $\mathrm{Na}^{+}, \mathrm{Ca}^{2+}$ e $\mathrm{Mg}^{2+}$.

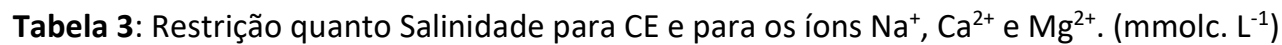

\begin{tabular}{|c|c|c|c|}
\hline \multirow[t]{2}{*}{ Parâmetros } & \multicolumn{3}{|c|}{ Restrição de uso } \\
\hline & Nenhuma & Moderada & Severa \\
\hline CE (dS. m-1) & $<0,7$ & 0,7 a 3,0 & $>3,0$ \\
\hline $\mathrm{Na}\left(\right.$ mmolc. $\left.\mathrm{L}^{-1}\right)$ & $<3,0$ & 3 & - \\
\hline $\mathrm{Ca}+\mathrm{Mg}\left(\mathrm{mmolc} . \mathrm{L}^{-1}\right)$ & $<5,0$ & 5,0 a 15,0 & $>15,0$ \\
\hline
\end{tabular}

Fonte: Ayers et al. (1991) adaptado por Almeida (2010).

A sodicidade e dada pelo conteúdo de sódio $\left(\mathrm{Na}^{+}\right)$na água. Seu uso como parâmetro de qualidade é devido a seu efeito sobre a permeabilidade do solo, e sobre a nutrição e toxicidade das plantas. Utiliza-se a 
Relação de adsorção de sódio (RAS), este índice denota a proporção relativa em que se encontra o $\mathrm{Na}^{+}$em

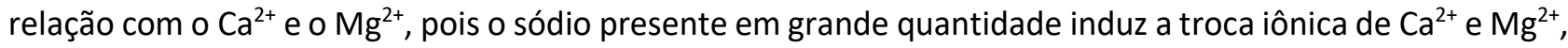
por íons $\mathrm{Na}^{+}$, tendo como consequência a degradação do solo pela perda de sua estrutura e permeabilidade. (ALMEIDA, 2010). O risco de sodicidade foi avaliado empregando a razão de adsorção de sódio (RAS) proposta por (AYERS et al., 1991), que é utilizada para prever melhor o problema de infiltração causado por concentrações relativamente altas de sódio ou baixas de cálcio e magnésio nas águas de irrigação os valores de restrição de uso estão na tabela 4. A RAS foi calculada (Equação 1) com os dados de $\mathrm{Ca}^{+2}, \mathrm{Mg}^{+2} \mathrm{e} \mathrm{Na}^{+}$ transformados de $\mathrm{mg} \mathrm{L}^{-1}$ para meq $\mathrm{L}^{-1}$ que é numericamente igual a mmolc $\mathrm{L}^{-1}$ (QUEIROZ, 2018).

Equação1: Cálculo da Razão de Adsorção Sódio.

$$
R A S=\frac{N a^{+}}{\sqrt{\frac{C a^{+2}+M g^{+2}}{2}}}
$$

Em que:

RAS é a Razão de Adsorção de Sódio, $\left(m m o l c L^{-1}\right)^{0,5}$ $\mathrm{Ca}^{+2}$ é a concentração de cálcio, mmolc L $\mathrm{L}^{-1}$; $\mathrm{Na}^{+}$é a concentração de sódio, mmolc $\mathrm{L}^{-1}$ $\mathrm{Mg}^{+2}$ é a concentração de magnésio, mmolc $\mathrm{L}^{-1}$

A toxicidade ocorre quando determinados íons, absorvidos principalmente pelas raízes, se acumulam nas folhas mediante a transpiração, chegando a alcançar concentrações nocivas. Certos elementos, inclusive em concentrações baixas, têm efeitos tóxicos para os vegetais, sendo principalmente os íons cloreto, sódio e boro os que podem causar toxicidade entre aqueles normalmente encontrados nas águas de irrigação (ALMEIDA, 2010). A toxicidade das águas para a irrigação foi avaliada quanto à presença dos íons cloretos, e a razão de adsorção de sódio, que em algumas concentrações podem ter efeitos tóxicos em algumas culturas. Foram definidas três classes de risco quanto à toxicidade das plantas (AYERS et al., 1991).

Tabela 4: Restrição quanto a Toxicidade e para os íons de sódio e cloreto (mmolc. $\mathrm{L}^{-1}$ ).

\begin{tabular}{|l|l|l|l|}
\hline Parâmetros & Restrição de uso & \multicolumn{2}{l|}{} \\
\hline $\mathrm{Na}^{+}$RAS & Nenhuma & Ligeira & Moderada \\
\hline Irrigação superficial & $<3$ & 3 a 9 & $>9$ \\
\hline Irrigação por aspersão & $<3$ & 1,2 a 0,3 & - \\
\hline $\mathbf{C l}^{-}\left(\right.$mmolc. $\mathbf{L}^{-1}$ ) & Nenhuma & Ligeira & Moderada \\
\hline Irrigação superficial & $<3$ & 4 a 10 & $>10$ \\
\hline Irrigação por aspersão & $<4$ & $>3$ & - \\
\hline
\end{tabular}

Fonte: Adaptado de Pizarro (1996) e Almeida (2010).

Quanto ao parâmetro microbiológico foram consideradas as bactérias do grupo coliforme termotolerantes que são indicadores de contaminação (LIBÂNIO, 2005). A Escherichia coli, uma das bactérias do grupo Coliformes Termotolerante, é eliminada em grande quantidade nas fezes de seres humanos e de animais homeotérmicos, e que nos garante uma poluição exclusivamente fecal, sendo utilizado como indicador de poluição (SILVA et al., 2017). A resolução do CONAMA 357/2005 determina que a contagem de coliformes termotolerantes não deverá ser excedido um limite de 1.000 coliformes termotolerantes por 100 mililitros para corpos d'água enquadrados como classe 2 .

A Resolução do CONAMA 357/2005 determina valores de pH na faixa de 6 a 9 para qualidade de água. Porém, para água de irrigação os estudos indicam que a faixa ideal de PH deve estar entre 6,5 e 8,4, valores fora dessa faixa pode indicar a presença de íons tóxicos que podem afetar negativamente a população 
microbiana do solo e causar danos ao sistema de irrigação (ALMEIDA, 2010).

\section{RESULTADOS E DISCUSSÃO}

Os resultados obtidos apontam que a qualidade da água da bacia do Rio das Garças no período estudado não apresentou nenhuma restrição de uso para irrigação, (Tabela 5) os valores de pH dos pontos analisadas não ultrapassaram os valores de pH entre 6,5 a 8,4, considerados referencias para a irrigação, valores abaixo de 7 próximos de zero no $\mathrm{pH}$ indicam aumento da acidez, e o poder de corrosividade e agressividade da água, o que pode levar à deterioração das tubulações e peças por onde essa água passa, enquanto valores acima de 7 a 14 indicam aumento da alcalinidade e podem levar ao surgimento de incrustações em tubulações

Tabela 5: Resultados da análise da água para irrigação da Bacia do Rio das Garças.

\begin{tabular}{|c|c|c|c|c|c|c|c|c|c|c|}
\hline & & $\mathrm{Na}^{+}$ & $\mathrm{Mg}^{2+}$ & $\mathrm{Ca}^{2+}$ & Ca e Mg & RAS & CE & E. coli & $\mathrm{pH}$ & $\mathrm{Cl}^{-}$ \\
\hline & & $\mathrm{mmolc} / \mathrm{L}$ & $\mathrm{mmolc} / \mathrm{L}$ & $\mathrm{mmolc} / \mathrm{L}$ & $\mathrm{mmolc} / \mathrm{L}$ & $\mathrm{mmolc} / \mathrm{L}$ & $\mathrm{dS} / \mathrm{m}$ & $\mathrm{NMP} / 100 \mathrm{~mL}$ & & $\mathrm{mmolc} / \mathrm{L}$ \\
\hline \multirow{6}{*}{ 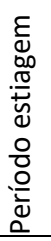 } & P1 & 0,010 & 0,266 & 0,205 & 0,471 & 0,0206 & 0,049 & 369 & 8,38 & 0,018 \\
\hline & P2 & 0,008 & 0,042 & 0,045 & 0,087 & 0,0384 & 0,018 & 199 & 7,19 & 0,009 \\
\hline & P3 & 0,022 & 0,125 & 0,115 & 0,240 & 0,0635 & 0,003 & 63 & 7,67 & 0,013 \\
\hline & P4 & 0,017 & 0,090 & 0,110 & 0,200 & 0,0538 & 0,026 & 135 & 7,98 & 0,010 \\
\hline & P5 & 0,078 & 0,058 & 0,060 & 0,118 & 0,3211 & 0,026 & 987 & 7,64 & 0,045 \\
\hline & P6 & 0,017 & 0,083 & 0,100 & 0,183 & 0,0562 & 0,026 & 216 & 7,97 & 0,009 \\
\hline \multirow{6}{*}{ 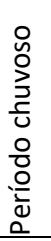 } & P1 & 0,008 & 0,206 & 0,177 & 0,383 & 0,0183 & 0,039 & 20 & 7,06 & 0,018 \\
\hline & $\mathbf{P 2}$ & 0,008 & 0,03 & 0,032 & 0,062 & 0,0454 & 0,018 & 231 & 7,54 & 0,009 \\
\hline & P3 & 0,008 & 0,078 & 0,081 & 0,159 & 0,0284 & 0,024 & 1313 & 7,36 & 0,013 \\
\hline & P4 & 0,008 & 0,061 & 0,086 & 0,147 & 0,0295 & 0,025 & 243 & 6,99 & 0,015 \\
\hline & P5 & 0,076 & 0,061 & 0,078 & 0,139 & 0,2883 & 0,035 & 2359 & 6,63 & 0,066 \\
\hline & P6 & 0,010 & 0,060 & 0,084 & 0,144 & 0,0373 & 0,024 & 1017 & 7,14 & 0,016 \\
\hline
\end{tabular}

Os resultados da condutividade elétrica, parâmetro relacionado com a concentração de sais e consequentemente com o risco de salinização, os valores encontrados indicam baixo teor de sais, segundo Ayers et al. (1991), água com condutividade elétrica menor que $0,7 \mathrm{dS} / \mathrm{m}$ não oferece nenhuma restrição para uso na irrigação e nem risco de salinidade, resultados semelhantes foram encontrados por Carneiro et al. (2012), ao analisar as águas do Rio Jaguaribe para uso agrícola no estado do Ceará. Os resultados de $\mathrm{Na}^{+}$ e RAS encontrados também indicam baixo risco de sodicidade. Em relação à toxicidade do íon cloreto, os valores enquadram as águas como nenhuma restrição quanto à toxicidade deste elemento.

Para os parâmetros microbiológicos, alguns pontos no período chuvoso apresentaram valores de E.Coli acima do permitido pela Resolução 357 do CONAMA que é de 1000 NPM/100mL, pra águas de classe 2, Figura 1. Este tipo de bactéria existe em grandes quantidades nas fezes de humanas, e quando encontrados na água, indica que a mesma recebeu carga de esgoto doméstico. Em um trabalho semelhante de Ribeiro et al. (2017) na Bacia Hidrográfica do Rio São José dos Dourados/SP, os maiores valores encontrados de Escherichia coli foram no período posterior a ocorrência de precipitações intensas, provavelmente devido ao aumento do escoamento superficial e lavagem do solo pelas chuvas, intensificando o transporte de sedimentos e matéria orgânica ao curso d'água. 


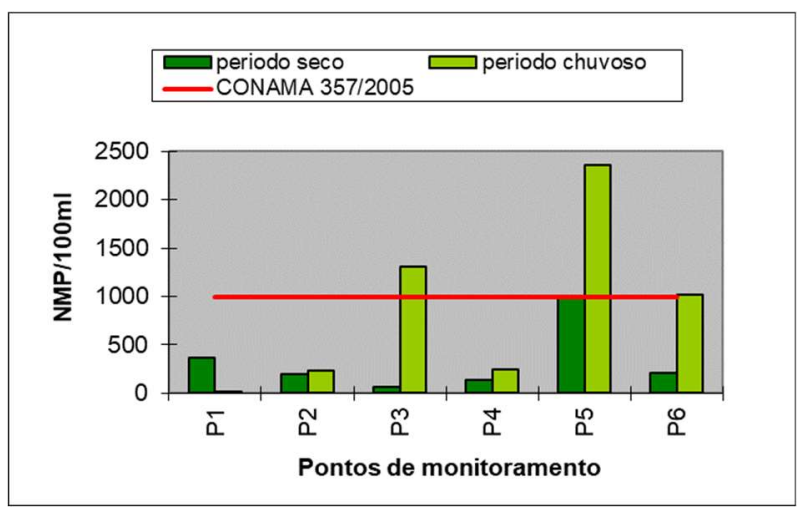

Figura 1: Variação de E.Coli no período.

A irrigação é uma prática de grande importância para o sucesso da produção de hortaliças, mesmo em regiões sujeitas a períodos de estiagem relativamente curtos e a presença da Escherichia coli na água da irrigação, poderá representar um sério risco a saúde, uma vez que são capazes de provocar distúrbios gastrintestinais em seres humanos principalmente ao consumir às hortaliças, que crescem rente ao solo e são consumidas cruas (BELIZÁRIO et al., 2014).

\section{CONCLUSÕES}

A análise dos dados de qualidade para uso agrícola busca sua caracterização com base nos potenciais danos aos sistemas de irrigação como entupimento de aspersores e obstruções; nas possíveis modificações das características físico-químicas do solo; dos prejuízos para as culturas irrigadas em termos de toxicidade e as condições sanitárias para o consumo humano. A bacia hidrográfica do Rio das Graças sofre os impactos da ocupação urbana que tem como consequência a deterioração da qualidade de suas águas, porém para uso na irrigação, de acordo com resultados encontrados no período estudado, não apresentou nenhuma restrição de uso.

AGRADECIMENTOS: à Secretaria de Estado de Meio Ambiente de Mato Grosso (SEMA/MT), ao Programa de Mestrado Profissional em Rede Nacional em Gestão e Regulação de Recursos Hídricos - Prof. Água, Projeto CAPES/ANA AUXPE № 2717/2015, pelo apoio técnico científico aportado até o momento.

\section{REFERÊNCIAS}

ANA. Agência Nacional de Água. Panorama da qualidade das águas superficiais do Brasil. Brasília: ANA, 2012.

ALVAREZ, V. M.; LEYVA, J. C.; VALERO, J. F.; GÓRRIZ, B. M.. Economic assessment of shadecloth covers for agricultural irrigation reservoirs in a semi-arid climate. Agric Water Manage, v.96, n.9, p.1351-9, 2009.

APHA, American Public Health Association. Standart Methods for the Examination of Water. 21 ed. Washington: APHA, 2005

AYERS, R. S.; WESTCOT, D. W.. A qualidade da água na agricultura. Estudos FAO. Irrigação e Drenagem. Campina Grande: UFPB, 1991.
ALMEIDA, O. A.. Qualidade da água de irrigação. Brasília: Embrapa Mandioca e Fruticultura, 2010.

BELIZÁRIO, T. L.; SOARES, A. M.; ASSUNÇÃO, W. L.. Qualidade da água para irrigação no projeto de assentamento Dom José Mauro, Uberlândia-MG. Revista Getec, v.3, n.5, p.53-73, 2014

BRAGA, B.; PORTO, M.; TUCCI, C. E. M.. Monitoramento de quantidade e qualidade das águas. In: REBOLÇAS, A. C.; REBOUÇAS, A. C.. Águas doces do Brasil. 3 ed. São Paulo: Escrituras, 2006. p.145-160.

CARNEIRO, M. F. C.; INGA, M. A. M.; SILVA FILHO, H. A.; SANTOS, E. V. M.; ROLIM, H. O.; CHAVES, J. R.. Avaliação da Qualidade da Água para Irrigação no Perímetro Irrigado 
Jaguaribe Apodi no Município de Limoeiro do Norte/Ce. In: CONGRESSO NORTE-NORDESTE DE PESQUISA E INOVAÇÃO, 7. Anais. Palmas, 2012.

CONAMA. Conselho Nacional do Meio Ambiente. Resolução n.357, de 17 de março de 2005. Brasília: CONAMA, 2005.

COSTA FILHO, U. A.. Análise comparativa dos indicadores de impureza e de qualidade da água nos períodos de seca e de cheia: Estudo de caso do Ribeirão João Leite e o Rio Meia Ponte em Goiânia/GO. Tese (Dissertação) - Universidade Católica de Goiás, Goiânia, 2006.

IBGE. Instituto Brasileiro de Geografia e Estatística. Censo 2010. Rio de Janeiro: IBGE, 2010.

LIBÂNIO, M.. Fundamentos de Qualidade e tratamento de água. Campinas: Átomo, 2005.

OLIVEIRA, L. N.. Qualidade da água do rio Poti e suas implicações para atividade de lazer em Teresina/PI. Revista Equador, Teresina, v.3, n.1, p.128-147, 2014.

QUEIROZ, T. M.; MELO, M. T.; FERREIRA, F. S. Qualidade da água para irrigação na comunidade quilombola Vão Grande, município de Barra do Bugres/MT. Rev. Brasileira de Agricultura, Fortaleza, v.12, n.3, p.2613-2620, 2018.

RIBEIRO, L. G.; NOGARINI, E. C. M.; PINHEIRO, J. E. P. A.. Qualidade microbiológica da água na bacia hidrográfica do rio São José dos Dourados/SP. Caminhos de geografia, v.18, n.6, 2017.

SEMA. Secretaria de Estado do Meio Ambiente. Relatório de Monitoramento da Qualidade da Água da Sub-bacia do Rio das Garças/MT. Cuiabá: IOMAT, 2006.

SILVA, M. A.; ARAÚJO, R. R.. Análise temporal da qualidade da água no córrego limoeiro e no rio Pirapozinho no Estado de São Paulo/Brasil. Formação, v.1, n.24, 2017.

A CBPC - Companhia Brasileira de Produção Científica (CNPJ: 11.221.422/0001-03) detém os direitos materiais desta publicação. Os direitos referem-se à publicação do trabalho em qualquer parte do mundo, incluindo os direitos às renovações, expansões e disseminações da contribuição, bem como outros direitos subsidiários. Todos os trabalhos publicados eletronicamente poderão posteriormente ser publicados em coletâneas impressas sob coordenação da Sustenere Publishing, da Companhia Brasileira de Produção Científica e seus parceiros autorizados. Os (as) autores (as) preservam os direitos autorais, mas não têm permissão para a publicação da contribuição em outro meio, impresso ou digital, em português ou em tradução. 